\title{
Witnessing the Unspoken Truth: On Residential School Survivors' Testimonies in Canada
}

\author{
Kamelia Talebian Sedehi \\ Sapienza University of Rome, Italy
}

\begin{abstract}
Residential schools functioned from 1876 to 1996 in Canada in order to assimilate Indigenous children to Euro- Canadian culture. By implementation of Indian Act (1876), the Indigenous children were taken away from their parents and sent to these schools. The trauma that these kids underwent as a result of physical, mental and sexual abuse at these residential schools has not been discussed by the survivors for many years. Therefore, the current research will focus on ten testimonies by the survivors of residential schools which have been selected from YouTube in order to indicate how their school days experience was narrated to the listener. The survivors of residential schools were witnesses of those incidents and they need a listener to vocalize what remained unspoken for long. The concept of trauma by Judith Herman and testimony and witnessing by Laub and Felman will be discussed while listening to these testimonies by the survivors.
\end{abstract}

Index Terms—residential schools in Canada, trauma, testimonies

\section{INTRODUCTION}

"'If the Greeks invented tragedy, ... the Romans the epistle and the Renaissance the sonnet,' writes Elie. Wiesel, 'our generation invented a new literature, that of testimony' (Felman and Laub, 1991, p. 17). We are witness of incidents that happen throughout history and there are so many questions regarding those incidents that were never asked to find their answers. There is a connection between history, art, memory, and survival which the following research intends to explore by delving into residential school incidents in Canada. By listening to testimonies of survivors of residential schools, which remained unspoken for long, the listener can trace trauma in human narrative. The selected testimonies by the survivors were produced as a result of residential school incidents. The current research will emphasize that even though the last residential school was shut down in 1996, its repercussions in the history still affect the Aboriginal community in every aspect. One can notice that as a history, the incidents are not over and its traumatic consequences are evolving in political, historical, and cultural aspects of Canadian society. They might have marked shutting down of last residential school as the end of suffering for Aboriginal community, but its fluctuations are still remained and they need to be remembered. As Felman and Laub observe "testimony has become a crucial mode of our relation to events of our times- our relation to trauma of contemporary history" (1991, p. 5), and my research intend to delve into the trauma that First Nation kids underwent at residential schools in Canada.

Residential schools were founded by Canadian federal government and administrated by churches to deracinate Aboriginal children from their culture, language, tradition and spiritual beliefs. The Euro- Canadian system considered Aboriginal culture as inferior and through residential schools, they intend to assimilate Aboriginal children to EuroCanadian society. Residential schools functioned from 1883 to 1996.

Although one could write a history of indigenous boarding schools in North America that dates to the $16^{\text {th }}$ century Colegio de Santa Cruz de Tlateloco, histories of those schools typically focus on a period that began in late $19^{\text {th }}$ century. This era was marked by the convergence of three phenomena- laws in the United States and Canada that made education mandatory, assimilationist education models designed to create uniform citizenries and scientific racism. (Dawson, 2012, p. 81).

Based on Canadian Policy, the children were taken away from their parents and sent to schools where they were forbidden to talk about their culture, language or community in general. These students were very young, sometimes they were just four years old. For any minor mistake that they made, they were punished severely by the staff. Over 100,000 children passed through the system of 125 schools over a century (MacDonald, 2007, p. 1001). At residential schools, Aboriginal children underwent physical, sexual and mental abuses. The training was not sufficient for those children to be prepared for white collar jobs; it focused on manual labor and domestic work.

Aboriginal culture was overlooked and belittled by residential school system and this attitude affected Aboriginal community for generations. The loss of culture and language were the consequences of those schools. As the kids were taken away from their families, they were deprived of nurturing family; therefore, they could not raise their own children with success. Since the main purpose of Canadian government and church was to eradicate Aboriginal culture, tradition and language in them, residential schools were considered as cultural genocide.

Since the Europeans settled in Canada, they assumed that their culture and civilization are superior to the natives. They believed that the first inhabitants in Canada are savage, ignorant and wild and they needed to be civilized and educated. Therefore, the government intended to civilize the Aboriginal people. 
Nicholas Flood Davin, journalist and politician, had the duty to study the residential school system of Natives in the United States and report it to Prime Minister Sir John A. Macdonald. Davin believed that the aboriginal can be civilized if they teach them while they are very young. From 1880s, the government started establishing residential schools across Canada. The children were sent to school which was far from their own family in order to alienate them from their community. Based on Indian Act (1876), the Aboriginal children were forced to go to residential schools by law. Once at school, the students got their haircut, wore uniforms and had their fixed schedule. Boys and girls were separated and siblings were not allowed to interact. Besides the Indian Act, there was a 'pass system' which was never codified in Indian Act, but it was enacted within society. Based on this system, the Aboriginals were separated from the settlers. They could only merge with settlers once they have the travel permit, named pass. As Miller mentioned "'the pass system prohibition of potlatch and dances and directed cultural change through residential schooling were much less effective than generally thought" (1990, p. 386). Based on this pass, cultural ceremonies, hunting, and commerce were affected. The residential schools and pass system affected the Aboriginal community and future generations.

The residential schools were underfunded and teachings were mainly about practical skills such as domestic services and manual labor. The mornings were devoted to classes and in the afternoon, the students were supposed do some chores. When the students were 18, they were sent away and discouraged to pursue further education.

Physical abuse was very common at residential schools. The students were beaten, strapped or shackled to their beds. The severe punishment, malnutrition, overcrowding, and poor sanitation increased death toll at these residential schools. Based on Nagy and Sedhev residential schools was "a genocidal policy, operated jointly by the federal government of Canada and the Catholic Anglican, United and Presbyterian churches" (2012, p. 67). Some of these students died as a result of tuberculosis and cold weather since the health condition was very poor. The parents of these children were never notified of their death. Recently, "the missing children projects aimed at finding the names of all children who had died in the schools, the causes of the death, and places of burial" (Milloy, 2013, p. 12).

Besides corporal punishment, students were victims of assault and rape by staff and other students. Supreme Court Justice Douglas Hogarth called Plint, supervisor at Port Alberin Indian Residential school as a "sexual terrorist". As a result of huge number of incidents of rape at residential schools, they were called "institutionalized pedophilia" (Fournier and Crey, 1997, p. 7). Moreover, chair Justice Murray Sinclair described Indian Residential schools as "one of the darkest, most troubling chapters in our nation's history, especially, he continues because its target and its victims were the most vulnerable of our society: 'little children'" (Cassell, 2017, p. 125). By 1950s, government and church noticed that despite the harm that was done to Aboriginal culture and language, it still survived. Moreover, they noticed the devastating effects of residential schools on Aboriginal students. In 1951, the half day school work was abandoned.

The Aboriginal kids were allowed to stay with their families wherever possible and more of qualified teachers were hired. In 1969, the Department of Indian affair started to control the system and church was not allowed to be involved in the teaching anymore, however, abuse continued.

Meanwhile, the government allowed the Aboriginal children to enter public schools. Though they could gain higher level of education, they still faced problem. The discrimination troubled Aboriginal children and they had difficulties adjusting to Euro- Canadian system. The Aboriginal students were discouraged to go to universities.

The last residential school was closed in 1996, but its effects troubled not only the school survivors, but also their future generations. The burden influenced various generations in Aboriginal communities. Loss of culture, language heritage, and broken family ties and personal trauma are just some of the consequences of residential schools in Aboriginal communities. Since they grew up in abusive condition, and they lacked nurturing environment, they abuse their own children and family members. Domestic violence among Aboriginal families led to dysfunction over generations. Intergeneration trauma is the type of trauma that these survivors of residential schools suffer from which results in their lack of parenting skills, and myriad of social problem (MacDonald and Hudson, 2012, p. 432).

Since Aboriginal culture and civilization was belittled by the staff at residential schools, the survivors, have very low self- esteem, and carry the sense of worthlessness. Low self- esteem led these survivors and future generations to alcoholism, substance abuse and suicide. Moreover, Aboriginal kids struggle to fit in Euro- Canadian society, but discriminations stop them to improve in Euro- Canadian system. Besides, they do not belong to their own community since they forgot their culture and language. They are misfits in either of communities. Based on social identity theory, "identification with two distinct cultures is problematic for identity formation because of conflicts in attitudes, values and behaviors" (Goodwill and MacCormick, 2012, p. 23), as a result, the Aboriginal people are lost in between Aboriginal culture and Euro- Canadian one.

In 1980s, residential school survivors took government and church to the court for whatever damage has been done to them.

In 1988 the Act for Preservation and Enhancement of Multiculturalism in Canada was passed. It emphasizes the racial diversity of Canadian society and its objectives include fostering appreciation of minority cultures and preserving languages other than English and French. (Hanmill, 2007, p. 27- 28)

In 2005, the federal government apologized for the damage done to Aboriginal community. The apology was the first step for healing process, but without action, apology would not be enough. About 1990s, the former students asked for compensation from the government for the acknowledgement of their suffering. \$1.9 billion was granted to the survivors of residential schools by the federal government in 2005. "Almost 38,000 former living students have applied 
under the 2006 settlement for compensation for serious physical and sexual abuse" (Roach, 2014, p. 566). Prime Minister Stephen Harper apologized to all former students of residential schools in 2008. Besides, Prime Minister Justin Trudeau apologized to survivors of residential schools in Newfoundland and Labrador in 2017. Despite all the past few attempts to "obtain redress have been made but Canadian law has frequently failed to appreciate the full scope of the harms of residential schools" (Roach, 2014, p. 566).

Since the government is not successful enough to help the Aboriginal people, "Indian people employed strategies of resistance, evasion and defiance to counter attempt to control their lives" (Miller, 1990, p. 386). There are some texts that were written by Aboriginal writers that deal with those residential schools and reflect the incidents. "Inuit writer Anthony Apakark Thrasher, Mi'kmaq poet Rita Jones and Cree playwright and novelist Tomson Highway" are some of the examples of Aboriginal authors (Grauer, 2011, p.308). As the native writers deal with Native life, they contribute in surviving the native culture and tradition which can be a kind of resistance against the imposed culture on them (Griffin, 2001, p. 291). Besides writing novels and reminding Aboriginal people of their history, culture and language, their community resisted the force of settlers by fighting "against their subordinate status" and asserting "their rights of equality" (Elkin, 1969, p. 112). The aboriginal people honored and respected their culture through songs, dances, prayers and ceremonies (Patridge, 2010, p. 42). Despite the apologies by Prime Ministers in Canada, still there is so much to do for Aboriginal people. As Howard Walker mentioned in his testimony his daughter could not get scholarship to continue her education as she is Aboriginal; therefore she needs to work by day and study by night (2014). This research aims at giving awareness to the incidents happened at residential schools in Canada and giving courage to survivors of those schools and their generations to fight for their rights. The government needs to preserve Aboriginal culture and language. The Aboriginal language is under serious threat of extinction since there is not enough fluent speakers within Aboriginal communities (Moore and Macdonald, 2013, p. 703). Besides malnutrition among Aboriginal people and their community is caused by "malnutrition and hunger in Canada's residential schools" (Habkirk and Forsyth, 2017, p.143); therefore, "the health and well- being of First Nations and Innuit are negatively affected" (Dell and Seguin, 2011, p. 76). As residential school incidents led to survivors' trauma, the concept of trauma by Judith Herman and testimony and witnessing by Laub and Felman will be used to analyze testimonies.

The current research involves practice of watching and listening attentively. As such ten testimonies by survivors of residential schools in Canada have been selected. These testimonies have been published in YouTube and they are open to the public. The listeners to those testimonies are witnesses of survivors' experiences. Here, listening would be a challenge since the survivors will speak about what had remained unspoken or unspeakable for long. Therefore, it is the listeners' duty to be the objective witness and listen attentively to unfold the testimonial life accounts of residential school days in Canada. However, listening would be a challenge as the listeners would understand their own limits. Their sanity would be at risk since they would sympathize with those survivors deeply. Therefore, they need to know the hazards on their path in order to fulfill their professional task which is reaching testimonial resolution. As the witnesses of the testimonies are informed of the incidents, it would be their duty to preserve the knowledge they gained as the reality was kept hidden for long and now it is revealed and it can help the survivors to continue their life after the traumatic incidents.

The current paper on the one hand will uncover the relation between art and culture, and on the other the conscious and unconscious witnessing of historical events. Therefore, testimony acts as a witness of traumatic historical incidents. As the historic incidents are witnessed, they need to be preserved and it can be done through the process of textualization. As residential school incidents led to survivors' trauma, the concept of trauma by Judith Herman will be used to analyze the ten selected testimonies.

\section{DISCUSSION}

The listener to human's torment faces different challenges. He needs to go beyond words, and pay attention to silence and body languages. The victim's narrative might be fragmented which indicates the absence that was caused by traumatic incident. The listener testifies to the reality that had not come into existence yet, the reality of the incident is very compelling. Herman mentions that trauma is

A situation has not been satisfactorily liquated... until we have achieved, not merely an outward reaction through our movements, but also an inward reaction through the words we address to ourselves, through the organization of the recital of the event to others and to ourselves and through the putting of this recital in its place as one of the chapters in our personal history. (2015, p. 37)

Besides Felman and Laub confirm "to seek reality is both to set out to explore the injury inflicted by it- to turn back on, and to try to penetrate, the state of being stricken, wounded by reality and to attempt, at the same time, to reemerge from the paralysis of this state, to engage reality as an advent, as movement, and as a vital, critical necessity of moving on" (1991, p. 29). The historical narrative, and documentaries, related to traumatic incidents, might be available, but the overwhelming shock of the incident did not have its objective witness yet, and it is the listener's duty to listen attentively as the knowledge of the incident is being shared by its witness who asks for an attentive listener who believes in his words. Therefore, the survivor of an incident needs a listener who takes part in creation of the knowledge. Felman and Laub mention that "in the process of the testimony to a trauma, as in psychoanalytic practice, in effect, you often do not want to know anything except what the patient tells you, because what is important is the situation of 
discovery of knowledge- its evolution, and its very happening" (1991, p. 62). As the listener listens to traumatic events, he participates in the experience. He will sympathize with the victim and if he remembers his traumatic past meanwhile, then the objective witnessing cannot take place. Therefore, the challenge is sympathy with the victim and dealing with his memories and at the same time his own traumatic past. Even the silence counts in the process of witnessing. "Testimony is a form of remembering. The faculty of memory functions in the present to recall a personal history vexed by trauma that thwart smooth- flowing chronicle" (Langer, 1991, p. 21). This part, testimony, is based on recorded videos by residential school survivors in Canada which are archived in YouTube and are open to public. The videos indicate the severe impact of trauma on survivors of residential schools. By giving their testimonies, these survivors can perceive the depth of what really happened to them, register, remember and transmit it to the listeners.

As the listener listens to the victim's narrative, he sympathizes with him, but as the incidents are too far from the listener, he does not become the victim of those incidents. However, while carrying out his function as a witness, he struggles with his own past memories and he needs to deal with them properly in order to be an objective witness. Therefore, he is not only trauma victim's witness, but also witnesses his own past. He needs to be informed of the challenges on his way. The listener should know that the trauma victim is scared of facing his traumatic past, his anguished memory and the ordeal he underwent. At any point of time, he might turn to silence. Herman notes "the ordinary response to atrocities is to banish them from consciousness" $(2015, \mathrm{p}$. 1). The victims tend to go silent as they want to listen to their confessions about the traumatic incidents. Listening to themselves and confirming to themselves that those incidents have really happened is another ordeal for trauma patient; therefore, silence is a shelter to run to. The listener needs to know the silence he might face, respect it and wait for the victim to continue voluntarily.

Katherine Thomas, a woman in her late fifties, was narrating her 2 years residential school experience to the interviewer. Once asked about the moment that sticks out during her residential school incident, she had a lump in her throat. She held back her tears and went silent for a few seconds. She was overwhelmed by the magnitude of the catastrophe she was addressing and she started explaining about the separation from her mom and dad as the most horrible memory of those years. Her tone is low and still struggling to express the pain she underwent by that separation. The sound of her voice, her glance, and her body language speak volumes. As the interviewer participates in excavating the ruins of the past, he asks about the importance of keeping the memories of residential schools alive. "By the presence and involvement of the interviewers, who enable them for the first time to believe that it is possible, indeed, against all odds and against their past experience, to tell the story and to be heard" (Felman and Laub, 1991, p. 41), the victims gain courage to express their unspoken past. Thomas' tone changed to a higher tone. She seemed more determined and explained that the documentaries just depicted a small piece of the incidents. "It didn't really understand the impact they had on our lives and they just kinda accepted it and trying to make the best of life without really understanding how it affected like three generations of my family" (2018).

As Thomas expresses the pain of being deprived of her parents, Howard Walker, a man in his seventies, who spent almost ten years in two different residential schools, All Saints school in Prince Albert and Gordon school of Regina, narrates sexual abuse he underwent. Moreover, he was beaten by a big whip for speaking his own language. His body languages, holding his hands together and at times playing with his ring, express his fear and nervousness. He very randomly has eye contact with the camera which is the witness of his testimony. He confesses his shame of telling anyone about the incidents at school. As he goes on talking about his alcoholism as a consequence of the treatment he received at those schools, he gains a bit more confidence. He has more eye contact, but still he rests his hand at his waist which shows the difficulty he faces to tell his story. He cannot handle more than that. At the same time, having a listener encourages him to continue. He is not very optimist about the government and what it would do for Aboriginal community. He expresses "a promise from federal government is just like pouring water into a strainer" (2014). To clarify his point, he gives an example of her daughter who works as an officer and she has problems continuing her education, since the government does not give scholarship to Aboriginals. He finishes his interview with a question " I can't think how they expect us to be part of society if you gonna keep us down" (2014). With this question, he lets his audience think of the grand scale of the action that should take place to support the Aboriginal community. He is the author of his testimony through giving his video testimony to the audience. Besides, he is a historical subject as he is the source of historical incidents. As Laub and Hamburger mention the person who offers video testimonies is "both, past and present, a remembered past in the present" (2017, p. 152). He narrates the history of what happened in the past and its impact on present.

Littledeer, a woman of seventy eight years old, spent eight years at residential schools and she narrates how she faced the fright when a six years old girl died next to her and there was no visit from that little girl's parents since they were never notified. She still suffers from being the witness to the death of that little girl since "feelings of guilt are specially severe when the survivor has been a witness to the suffering or death of other people" (Herman, 2015, p. 54). The memory of little girl's death comes back to her consciousness and leaves her feel guilty. After all these years, she still held back her tears and goes to silence when she talks about getting mad at her parents for sending her to a school and the bad treatment she received there. She sent her kids to residential schools too and she shrugs her shoulders as she mentioned her sons need to be strong; there is no other way to tough out the experience. Through her narration, the witness would know how Indian habits, snaring rabbits and picking blueberries, were destroyed by white people. "We didn't bother white people but white people bothered me" (2015). Not only Aboriginal customs and traditions, but also 
mutual relationship between parents and children were severed by residential schools as Madeleine Dion Stout, sixty two years old, explains. She spent thirty six consecutive months at residential schools and calls those schools as "blood on Canadian landscape". As the kids become strangers to their native land and they had mentor stress once they left the school, she calls those schools as a shame. Her speech is mechanical. She narrates her story without showing any emotion and the only time she smiled throughout the whole interview was when she remembered the visit from her parents at residential schools. As a victim of residential school, she would like to make lasting difference for "residential school survivors, but the other little children who are having difficulties today" (2015).

As Walker experienced sexual abuse and beatings at residential schools, sixty two year old Mason, shared the beatings and sexual abuse experience with us too. He pinpoints that the teachers took advantage of teaching kids how to take shower and then abuse them sexually. Besides, he tells us about his deprivation of his mother tongue and he was beaten and his tongue was pulled out and punched. Moreover, he was wacked and strapped for talking to his siblings.

Likewise Karen Chaboyer who spent eight years at Saint Margaret residential school was wacked for getting attention of her siblings. She was deprived of her parents and her friends at the same time. She learned to be ashamed of being an Indian at residential school and she would go to hell just because she is Indian. Loss of identity and shame are the consequences of those years. She underwent grief counseling since she underwent grief and trauma. She is stranger to people to the extent that till now she has friends, but not a best friend. Trust is shattered for the survivors. While the listener listens to the testimony he shapes the testimony based on his understanding; moreover, the later recipients of testimonies interpret the testimony based on their understanding (Laub and Hamburger 2017, p. 153). Therefore, testimonies are not fixed but they depend on evolution and interpretation.

Michael Cheena, sixty two, explains how he was severely punished for stealing a slice of bread, but at the same time, he is the one among all the selected testimonies that said supervisors treated them with barbecue when they won the Champion. However, he also adds that he became an alcoholic since drinking alcohol is a coping mechanism. Herman notes that "traumatized people run a high risk of compounding their difficulties by developing dependence on alcohol or other drugs" (2015, p. 46). Survivors and their next generations use alcohol and drugs to forget about the pain they underwent during residential schools or their own parents; as the next generation of residential school survivors. He asks from all the Canadians, aboriginal or non-aboriginal, to learn about the true history of Canada. Herman believes "the victim demands action, engagement and remembering" (2015, p. 8). These survivors need listeners to listen to their stories and then take action for their protection.

Louise Longclow, sixty two, confirms that at times, she " just found kind of connection just not having some kind of memory at times and it all goes back to being robotic, no feeling, no emotion, no nothing" (2018). "The voluntary suppression of thoughts related to the traumatic event is characteristic of traumatized people" (Herman, 2015, p. 46). She was traumatized by being left alone and having no one to cuddle her or give her support. Therefore, trauma led her to amnesia. Her parents also had residential school experience and her mom was punched in her face for speaking her native language and even her tooth was protruded her upper lip as she was flown across the room. Her dad also told her about the hunger and how they learned to eat raw potatoes as it was the only way to sedate their hunger. She asks those who listen to her testimony to listen to her words attentively and believe in her and all the Aboriginal people. She is tormented even now since she cannot function as a parent, community member or any other kind of relationships.

In addition to Longclaws who listened to her parents' experience of residential schools, Mike Loft and Lorena Fontaine gave their testimonies as the next generations of survivors of residential schools. Neither of them felt safe at home with their parents as they underwent constant abuse by them. Herman points out that

The child trapped in an abusive environment is faced with formidable tasks of adaptation. She must find a way to preserve a sense of truth in people who are untrustworthy, safety in a situation that is unsafe, control in a situation that is terrifyingly unpredictable. (2015, p. 96)

Loft, fifty five years old sat with crossed arms, which indicates his defiant posture, tells us about the unpredictability of the punishment that he received from his father. "Children in an abusive environment develop extraordinary abilities to scan for warning signs of attack" (Herman, 2015, p. 99), and he still kept his defiant posture after years. His father spent eleven years at Spanish, Ontario and what he brought home was the fear that he imposed on his children. Loft testifies how survivors' children commit suicide these days rather than the survivors themselves. Moreover Fontaine expresses how her parents did not have any role models; therefore, she was a vulnerable kid.

The traumatic incidents that each of the survivors or their children underwent though belonged to real, it passed the normal reality. The traumatic moment does not have beginning, ending, middle, time or place. Its timelessness takes the victim away from comprehension. The trauma patient not only deals with the memories of the past, but also with the events that never ended completely; therefore, it still continues till the present time. The witness can perceive the incomplete events through their silence, body languages and their attempts to find a better way to explain themselves. The struggle they undergo to let the listener understand the depth and magnitude of tormenting moments they underwent. They all asked for a listener who believes in their words and understands their pain, plight and ordeal. "The testimony to the trauma thus includes its hearer, who is, to speak, the blank screen on which the event comes to be inscribed for the first time" (Felman and Laub, 1991, p. 57). Telling the stories let them articulate what remained unspeakable so that they can hear the reality of incidents themselves as well. They reassert the reality of incidents by articulating it to their witness which helps them to move to healing process. The recorded testimonial videos give 
opportunity to the listeners to historicize the events. Testimonies take place between two people, the survivor and the listener who the survivor waited for a long time and needed his presence to reaffirm the incidents to himself. Herman mentions that "the fundamental stages of recovery are establishing safety, reconstructing the trauma story, and restoring the connection between survivors and their community" $(2015$, p. 3$)$. Now that process of testimony is done, it is the responsibility and duty of Canadian federal government to support the survivors of residential schools and their following generations, though the survivors are not very optimist about the actions the government would take.

\section{CONCLUSION}

The residential school survivors mentioned that the support can help these survivors to survive the trauma they underwent days and nights. As Herman points out "the victim demands action, engagement and remembering" (2015, p. 7-8). The incidents that happened at those schools had ripple effects and deep harm and they should not be forgotten. As the society needs to take action and support the Aboriginal community, the residential school survivors need to unite and talk about their past and mention its hard truth about being uprooted from their communities and being stripped of their identity. They need to be heard as not only their generation, but also generation after generation the Aboriginal community was affected by the outcome of residential schools. The incidents should be told and retold until all the aboriginals receive the attention they deserve from their federal government only then the healing would be possible.

\section{REFERENCES}

[1] Cassell, Elizabeth. (2017). Canada's Residential Schools: The Final Report of the Truth and Reconciliation Commission of Canada. British Journal of Canadian Studies, 30 (1): 125- 127.

[2] Cheena, Michael. (2016). A residential school survivor shares his story of trauma and healing. The Globe and Mail. Retrieved January 2018 from https://www.youtube.com/watch?v=ddZEeeaozDE.

[3] Dawson, Alexander. S. (2012). Histories and Memories of the Indian Boarding Schools in Mexico, Canada, and the United States. Latin American Perspectives, 39 (5): 80- 99.

[4] Dell, C. A. and Maureen Seguin. (2011). From Benzos to Berries: Treatment Offered at an Aboriginal Youth Solvent Abuse Treatment Centre Relays the Importance of Culture. Canadian Journal of Psychiatry, 56 (2): 75-83.

[5] Elkin, Frederick. (1969). Advertising Themes and Quiet Revolutions: Dilemmas in French Canada. American Journal of Sociology, 75 (1): 112- 122.

[6] Fournier, Suzanne and Ernie Crey. (1997). Stolen from Our Embrace: The Abduction of First Nations Children and the Restoration of Aboriginal Communities. British Columbia: Douglas \& McIntyre.

[7] Goodwill, Alanaise. And Rod, O., McCormick. (2012). Giibinenimidizomin: Owning Ourselves--Critical Incidents in the Attainment of Aboriginal Identity. Journal of Counseling and Psychotherapy, 64(1): 21- 34.

[8] Grauer, Lally. (2011). Magic Weapons: Aboriginal Writers Remaking Community after Residential School. (Rev). University of Toronto Quarterly, 80 (2): 308- 310.

[9] Griffin, Gwen. (2001). Touring Indian Country: A Review of Native Fiction from 1999 and 2000. Western American Literature, 36 (3): 291- 303.

[10] Habkirk, Evan. J. and Janice Forsyth. (2017). Introduction: Reflections on Health and the Body at Canadian Indian Residential schools. British Journal of Canadian Studies, 30 (2): 143- 145.

[11] Hanmill, Faye. (2007). Canadian Literature. Edinburgh: Edinburgh University Press.

[12] Herman, Judith. (2015). Trauma and Recovery. New York: Basic Books.

[13] Langer, Lawrence. L. (1991). Holocaust Testimonies: The Ruins of Memory. New Haven and London: Yale University Press.

[14] Laub, Dori and Andreas Hamburger. (2017). Psychoanalysis and Holocaust Testimony, Unwanted Memories of Social Trauma. New York: Routledge.

[15] Laub, Dori and Shoshana Felman. (1991). Testimony; Crises of Witnessing in Literature, Psychoanalysis and History. London; Routledge.

[16] Littledeer, Alice. (2015). Stolen Children | Residential School survivors speak out. CBC News:The National. Retrieved January 2018 from https://www.youtube.com/watch?v=vdR9HcmiXLA\&t=10s.

[17] Loft, Mike. (2015). Stolen Children | Residential School survivors speak out. CBC News:The National. Retrieved January 2018 from https://www.youtube.com/watch?v=vdR9HcmiXLA\&t=10s.

[18] Longclaws, Louise. (2018). Residential school survivor explains the impact on her family. CBC News. Retrieved January 2018 from https://www.youtube.com/watch?v=nJ64DItsli0\&t=9s.

[19] MacDonald, David. (2007). First Nations, Residential Schools, and the Americanization of the Holocaust: Rewriting Indigenous History in the United States and Canada. Canadian Journal of Political Science, 40 (4): 995- 1015.

[20] MacDonald, David. B. and Graham Hudson. (2012). The Genocide Question and Indian Residential School in Canada. Canadian Journal of Political Science, 45 (2): 427- 449.

[21] Miller, J. R. (1990). Owen Glendower, Hotspur, and Canadian Indian Policy. Ethnohistory, 37 (4): 386- 415.

[22] Milloy, John. (2013). Doing Public History in Canada's Truth and Reconciliation Commission. The Public Historian, 35 (4): 10- 19.

[23] Nagy, Rosemary and Robinder Kaur Sedhev. (2012). Introduction: Residential school and Decolonization. Canadian Journal of Law and Society, 27 (1): 67- 73.

[24] Partridge, Cheryle. (2010). Residential schools: the Intergenerational Impacts on Aboriginal Peoples. Native Social Work Journal, 7: 33- 62.

[25] Roach, Kent. (2014). Blaming the Victim: Canadian Law and Causation and Residential schools. University of Toronto Law Journal, 64 (4): 566- 595. 
[26] Thomas, Katherine. (2018). Residential school survivor says being separated from her family was the worst. CBC News. Retrieved January 2018 from https://www.youtube.com/watch?v=bt6iOj_pkfw.

[27] Walker, Howard. (2014). Residential school survivor Howard Walker. MetroCanadaOnline. Retrieved January 2018 from https://www.youtube.com/watch?v=seHId1hKq_s.

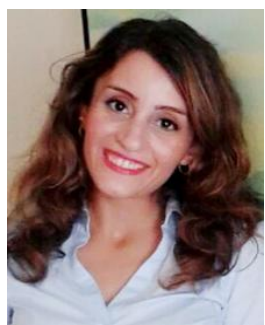

Kamelia Talebian Sedehi was born in Iran in 1987. She received her B.A. (2009) and M.A. (2011) in English Literature from University of Isfahan. She received her PhD (2016) English Literature from University Putra Malaysia. Currently, she is doing her second PhD at Sapienza University of Rome, Italy. Her publications include: The Melancholic Subject and The Bluest Eye, Beloved and Kristevan Melancholic Subject, and Natural Selection and The Cage and some other titles. Her research interests are trauma, melancholia, identity crisis, comparative studies and interdisciplinary topics. She has presented at various national and international conferences and is an experienced university lecturer and teacher. 